\title{
Transformation of business architecture as a result of globalization and glocalization processes.
}

\author{
Yaroslava Kostiuk ${ }^{1,2 *}$ \\ ${ }^{1}$ University of Zilina, Faculty of Operation and Economics of Transport and Communications, \\ Univerzitna 1, 01026 Zilina, Slovakia \\ 2 Institute of Technology and Business, Faculty of Corporate Strategy, Okruzni 517/10, 37001 Ceske \\ Budejovice, Czech Republic
}

\begin{abstract}
Research background: Globalization and glocalization processes undeniably have a major impact on the building and innovation of business architecture. The contribution is aimed at studying the effect of these processes on selected elements of business architecture, such as organizational and management structures, enterprise management, including strategic management and decision-making. The theoretical part is focused on the specification of globalization and glocalization processes and their effects on business architecture in general and in selected research area.

Purpose of the article: The objective of the paper is to use a sample of ca. 250 enterprises operating in manufacturing, industry, and services classified into size categories to determine the effect of globalization and glocalization processes on selected elements of business architecture.

Methods: The issue of changes in organizational and management structures is addressed using mathematical-statistical methods.

Findings \& Value added: It is obvious that the very concept of corporate strategy changes significantly, being transformed into business strategy through business models, and so does the theoretical background for generating corporate strategy on the basis of creating added value for customers within individual corporate processes. These statements, if confirmed by research, shall significantly influence strategic behaviour of managers in the management of enterprises. The conclusion part summarizes the outputs of the research activities presented in the contribution and specifies the expected development trends in the given issue.
\end{abstract}

Keywords: business architecture; globalization processes; glocalization processes; innovations of business architecture

JEL Classification: $F 6$; $F 610 ; M 2$

*Corresponding author: 26567@,vstecb.cz 


\section{Introduction}

In times of global competition, health and financial crisis, increasingly more enterprises start to consider whether their current corporate structure is able to achieve the business objectives set, and whether it will be able to achieve them in the future. Business architecture, or architecture of corporate processes is a model structure of a set of interconnected and integrating processes in an enterprise, which enable to understand the current business operations in the enterprise. Modelling of these processes is a basis for improving business strategies or for determining business opportunities for enterprises in the future (Moldagulova et al., 2020). Over the last two decades, the environment of prosperous enterprises has required consistency between business needs and information technologies (Gonçalves, 2021). This follows from the need of enterprises to keep looking for a solution to a specific problem, the need for optimizing processes and their integration into other sectors. Currently, we can see globalization and glocalization processes of corporate integration at the global level, covered by national, regional, and local business systems. The COVID-19 pandemic enables better identification and greater global inequalities (Stiglitz, 2021). The submitted contribution aims to determine the impact of globalization and glocalization processes on selected elements of business architecture in the selected manufacturing, industry, and services sectors.

\section{Literature review}

The globalization of economic interactions is a key trend in the development of the global economic system (Arkhipov and Yeletsky, 2021), characterized by strengthening and expanding links between national economies in the global market (Bucur et al., 2010), which represents the multinational integration of goods, services, and capital markets (Dumitrache, 2020). Globalization promotes a better multinational division of labour, more effective distribution of savings, and has a positive effect on increasing labour productivity (Radulović and Kostić, 2020). Despite the success of globalization processes, the processes of localization and regionalization strife for benefit of local structures, thus refuting the trends accentuating the globalization. The transformation of the global economy has led to an intensive development of the hybrid trend, specifically glocalization (Arkhipov and Yeletsky, 2021). The term "glocalization" was first used in the 1980s in explaining Japanese global marketing strategies (Iermakova, 2021). Lately, it was applied by economists in other economic trends. Arkhipov and Yeletsky, (2021) state that glocalization does not lead to the past but to economic isolation from historic forms, including the priority implementation of local economic entities' interests in the globalization processes and their processes subordinate to patters. In a broader sense, glocalization in the development of society, especially in the times of global economy, increases the role of factors and characteristics at the level of local entities.

The existence of globalization and glocalization processes enables innovations within the business sector and the transformation of organizational and management structures using business architecture. Business architecture (EA) provides integrated view to the whole corporate system and helps managers in effective and flexible decision-making on changes so that the enterprise is capable of long-term existence in the current global competitive environment (Gála et al., 2012). According to Buchalcevová (2008), business architecture is an approach, concept, method and tool to describe the fundamental arrangement of links between an enterprise and its information system. The interconnection of these links leads to achieving business mission when respecting the surrounding environment and consistently adhering to formulated principles of proposal and development of the system. Enterprise architect is responsible for the definition, implementation, and adaptation of business strategy 
and maintenance of business architecture (Gonçalves, 2021) with a focus on the global globalization and glocalization trends.

The transformation of business architecture is definitely influenced by the global economic development. The theory says that the globalization development takes place in a 50-year waves (Kislingerová and Nový, 2017). The first wave was associated with the use of steam, the second one with the development of railway and metallurgy. The third wave was characterized by the development of power engineering, chemistry, and automotive. Currently, we are at the end of the fourth wave, which is connected with the development of electrical engineering and other cutting-edge technologies, and we are expecting the fifth wave caused by the global economic development. According to researchers, the building of business architecture is divided into three main stages. In the first stage, business architects focus on the design of the organizational system. This is followed by the stage focused on the design of the organizational structure and processes. In the third development stage, business architecture responds to the ever-intensifying external changes in the enterprise surroundings and is focused on proposing a strategy using information technologies (Pártlová and Váchal, 2017; Pártlová and Straková, 2017). The current concept of business architecture is based on practice. The design and implementation of information systems in the business architecture includes the specification of corporate strategies, visualization of corporate processes and modelling of resource management processes, as well as the improvement of organizational structures, modification of information strategies, and creation of new business values (Zhi and Zhou, 2022). For researchers, architects, and developers, the modelling of business architecture is usually the first and at the same time the most important analytical step.

The development of business architecture models has undergone various modernizations within the $4^{\text {th }}$ globalization stage. The model of Zachman Framework is the oldest used concept of business architecture. The model has a clear matrix structure, which divides the architecture into basic dimensions with a degree of their detail. Zachman Framework (ZF) is currently wrongly considered surpassed by newer models, especially the TOGAF model. The main advantage of the ZF over the newer models is its clarity and good comprehensibility. On the basis of TOGAF, ArchMate language was created, whose structure corresponds to the original division of ZF. Looking at enterprise from the perspective of its architecture is currently more critical than in the past, since enterprises have started to apply the principles of service-oriented architecture (SOA) to a larger extent.

In the future, business architecture, whose integral part is the organizational and management structure of enterprises, will have an important role in achieving business objectives (Váchal and Talír̆, 2020) and improving the reputation of the enterprise. Based on the positive or negative reputation of the enterprise, employees naturally choose which company to work in, investors decide on which company they want to invest in, and customers choose a company from which they want to buy products or services (Soviar et al., 2019). There are many other factors affecting the effective selection of the organizational structure, such as the enterprise goals and strategy, size, life cycle, management style, technologies, social environment, enterprise culture, changes in the enterprise management, and changing managerial trends. From the perspective of the historical development of organizational and management structures in the Czech Republic (Váchal and Talír, 2020), the period before the World War II is considered to be a period of extended linear organizational structure with directive and centrist management. In the post-war period, there started to be applied line-personnel organizational structures with professional specifications, whose decline was connected with the liquidation of the majority of small and medium-sized enterprises in the Czech Republic. Since then, business sector has undergone many political, social, technological, demographic, natural, and health-related changes, whose globalization and glocalization processes affected enterprise decision-making on the selection of the 
optimal organizational structure, which would enable them to achieve their strategic goals. Within this research, our task is to determine the impact of these globalization and glocalization processes on selected elements of business architecture in the South Bohemian region by means of the following research questions:

RQ1: Is there a statistically significant dependence between the number of management levels and the type of organizational structure?

RQ2: Does the geographical scope of enterprises depend on the number of management levels?

RQ3: Is there a statistically significant dependence between the type of organizational structure and enterprise geographical scope?

Based on the formulated research questions, the following methodology chapter will determine the effect of globalization and glocalization processes on the transformation of the business architecture.

\section{Material and Methods}

The objective of the paper is to use a test sample to determine the effect of globalization and glocalization processes on the selected elements of business architecture. Using the formulated research questions, it will be possible to detect possible dependence between the following parameters with regard to the globalization process:

- The enterprise geographical scope,

- The number of management levels,

- The type of organizational structure.

The research sample contains 250 enterprises operating in the sectors of manufacture, industry, and services, divided into individual size categories, in the South Bohemian Region. The data obtained by means of a questionnaire survey conducted between 2018-2021 are processed by means of mathematical-statistical methods, which are used to address the issue of changing organizational and management structures. The data are analysed using the method intended for the categorical data, specifically the Chi-square statistics calculated in the statistical programme $\mathrm{R}$ (version 3.6).

Following the determined dependence between some parameters, more advanced mathematical-statistical modelling is applied using the Matlab programme (version 2021b) and the function Classification Learner, which trains the models of various qualifiers. With this application, various qualifiers can be used to examine machine learning and data, select functions, enter validation schemes, train models, and evaluate results. The results obtained are presented in the form of tables and graphs in the following chapter.

\section{Results}

Our qualitative research using mathematical-statistical methods is divided into two phases:

1. Analysis of the dependencies of individual variables according to the enterprise geographical scope.

2. Selection of classification model for the training dataset.

\subsection{Analysis of the dependencies of individual variables according to the enterprise geographical scope}

The analysis of qualitative research with the use of Pearson's Chi-squared test in the statistical programme $\mathrm{R}$ determined the dependence between individual variables according to the formulated research questions. 
RQ1: Is there a statistically significant dependence between the number of management levels and the type of organizational structure

Table 1. Dependence of numbers of management levels and type of organizational structure

\begin{tabular}{|c|c|c|}
\hline X-squared & df & p-value \\
\hline 65.178 & 36 & 0.002061 \\
\hline
\end{tabular}

Source: Author (2021)

The dependence between the number of management levels and the type of organizational structure was confirmed in the whole enterprise geographical scope. The analysis of the relationship is presented in Figure 1.

departmental management structure

combined management structure

divisional management structure

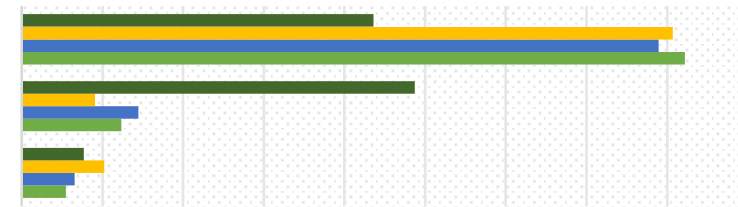

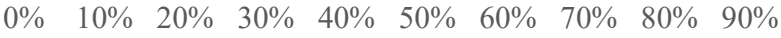

\begin{tabular}{|c|c|c|c|}
\hline & $\begin{array}{c}\text { divisional management } \\
\text { structure }\end{array}$ & $\begin{array}{c}\text { combined management } \\
\text { structure }\end{array}$ & $\begin{array}{c}\text { departmental } \\
\text { management structure }\end{array}$ \\
\hline - 4 level of management & $7.69 \%$ & $48.72 \%$ & $43.59 \%$ \\
\hline 3 level of management & $10.23 \%$ & $9.09 \%$ & $80.68 \%$ \\
\hline - 2 level of management & $6.58 \%$ & $14.47 \%$ & $78.95 \%$ \\
\hline 1 level of management & $5 \%$ & $12 \%$ & $82 \%$ \\
\hline
\end{tabular}

Figure 1. Relationship between number of management levels and type of organizational structure

Source: Author (2021)

The analysis of the relationship between the type of organizational structure and the number of management levels showed the predominance of the departmental organizational structure $(82 \%)$ over the divisional and combined management structure. The combined organizational structure is most typical for 4-level management structure.

RQ2: Does the enterprise geographical scope depend on the number of management levels?

Table 2. Dependence of enterprise geographical scope on number of management levels

Source: Author (2021)

\begin{tabular}{|c|c|c|}
\hline X-squared & df & p-value \\
\hline 40.465 & 6 & 0.000000369 \\
\hline
\end{tabular}

The relationship of the enterprise geographical scope and the number of management levels is confirmed. The analysis of the relationship is presented in Table 2. 


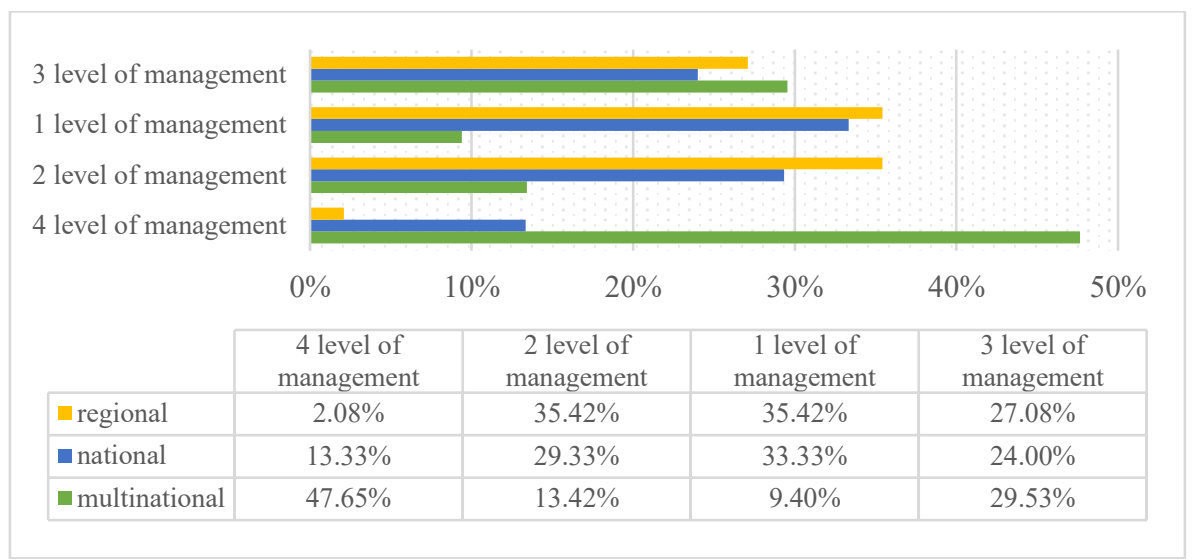

Figure 2. Relationship of enterprise geographical scope and number of management levels

Source: Author (2021)

The analysis of the relationship between the enterprise geographical scope and the number of management levels showed the predominance of multinational enterprises with 4 and more management levels $(47 \%)$ and 3 management levels (30\%). Local regional management prevails in 1- and 2-level management. The national enterprises are approximately at the same level, i.e. 13-34\% within all levels of enterprise management.

RQ3: Is there a statistically significant dependence between the type of organizational structure and the enterprise geographical scope?

Table 3. Relationship between enterprise geographical scope and type of organizational structure

Source: Author (2021)

\begin{tabular}{|c|c|c|}
\hline X-squared & df & p-value \\
\hline 27.462 & 24 & 0.2834 \\
\hline
\end{tabular}

Relationship between the enterprise geographical scope and the type of organizational structure is not confirmed. The analysis of the relationship is presented in Table 3 .

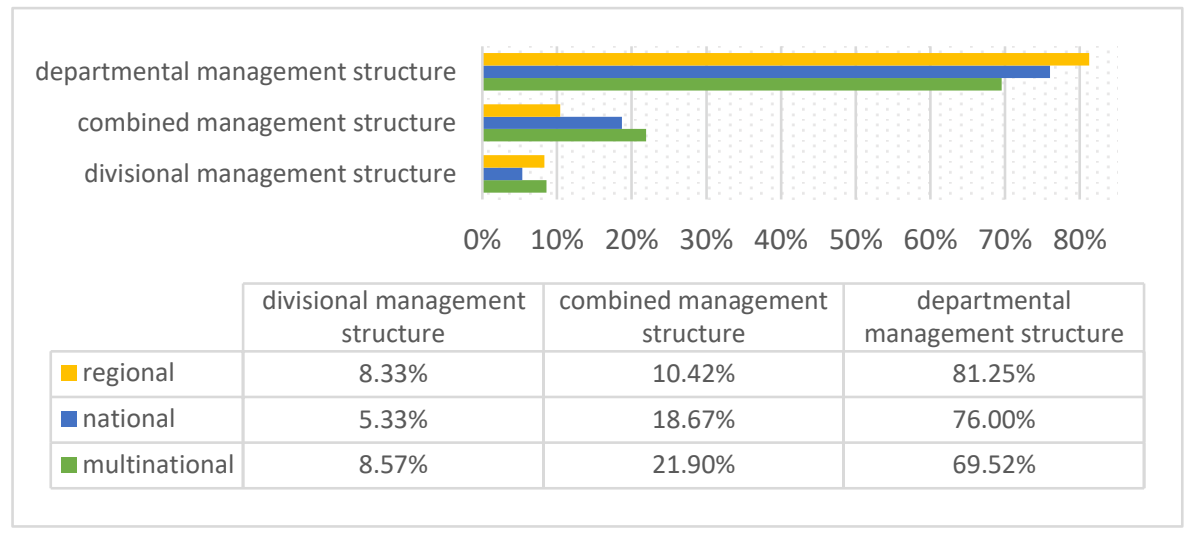

Figure 3. Relationship between enterprise geographical scope and type of organizational structure Source: Author (2021) 
The analysis of the relationship between the type of organizational structure and the enterprise geographical scope showed the predominance of departmental management structure at approximately all three forms of the enterprises' geographical scope (70-80\%). In the case of the combined management structure, multinational form of organizational management structure prevails.

\subsection{Selection of classification model for training dataset}

Based on the above analysis of the dependence of individual variables according to the enterprise geographical scope performed using the statistical programme $\mathrm{R}$ and then the statistical software Matlab, it was possible to identify a model that would most accurately describe the logic of the training model in order to achieve the research objective. The results of the classification model training are presented in Table 5.

Table 5. Results of KNN classification model training - Medium KNN

\begin{tabular}{|l|l|}
\hline Accuracy (Validation) & $76,4 \%$. \\
\hline Total cost (Validation) & 65 \\
\hline Prediction speed & $13000 \mathrm{obs} / \mathrm{sec}$ \\
\hline Training time & $0.34695 \mathrm{sec}$ \\
\hline
\end{tabular}

Source: Author (2021)

Using the method of Classification Learner, the KNN classification model (Medium KNN) was identified, which achieved the best results and the predictive accuracy of $76.4 \%$. The predictive accuracy of the model is reflected by the Confusion matrix (number means number of observations), which shows the rate of correct and false positive results of data training. Within the created model, the function Validation Roc Curve was used to identify the influence of the enterprise geographical scope on the departmental management structure (Figure 5) and combined management structure (Figure 6).

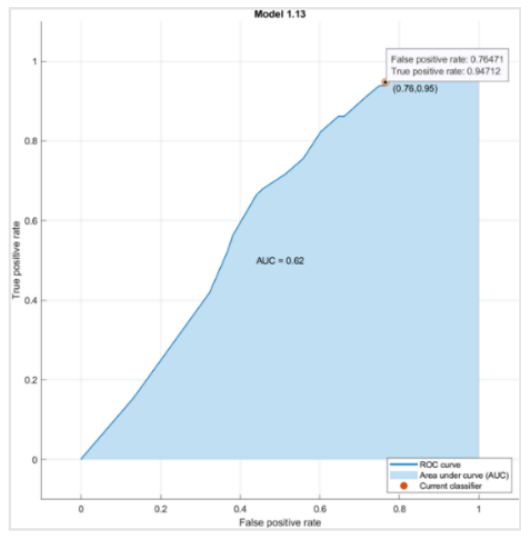

Figure 5. Function Validation Roc Curve

for departmental management structure

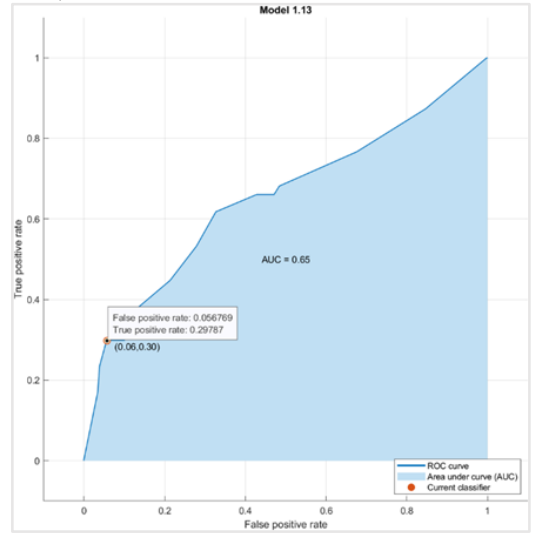

Figure 6. Function Validation Roc Curve

for combined management structure

According to the graphical representation of the function Validation Roc Curve for departmental management structure, the results showed that that within the training, the model participated correctly in $94 \%$ of cases; in the case of combined management structure, it was only $29 \%$. The effect of globalization was thus greater in the case of combined management structure. In contrast, in the case of departmental management structure, there was confirmed greater effect of the local geographical scope of the enterprise. 


\section{Discussion}

Within the research, we determined the effect of globalization and glocalization processes on the selected elements of business architecture using the analysis of relationships of individual variables and enterprises' geographical scope. Based on the analysis performed, it is possible to answer the formulated research questions. For the purposes of the research, multinational enterprises are considered to be influenced by the globalization processes. Regional and national enterprises are considered to be influenced by glocalization processes.

The analysis of the relationship between the number of management levels and the type of organizational structure showed that in the period under review, the departmental management structure prevails. In the case of combined management structure, the organizational structure with 4 or more levels of management prevails.

The analysis of the relationship of the geographical scope and the number of management levels showed a significant influence of globalization processes in the case of 3 and 4-level management structure in the case of multinational companies, while the effect of glocalization processes was recorded mostly in the case of 1 and 2-level management structure in regional and national enterprises.

The analysis of the enterprise geographical scope and organizational structure showed the predominance of the departmental management structures in all forms of geographical scope of enterprises (regional, national, and multinational). In terms of the departmental management structure, there is a predominance of regional enterprises influenced by local and glocalization processes. The second most frequent structure is the combined management structure with the predominance of multinational enterprises influenced by globalization processes.

In this research, we dealt with the statistical confirmation of the expected dependence of elements within the selected analysed elements of business architecture (geographical scope of enterprises, the levels of management structure, and the type of organizational structure). Based on the results achieved, it can be stated that the globalization and glocalization processes result in the gradual transformation of business architecture, which leads to the development and gradual transition from a centrally-planned economy to the market economy.

Within the given research, one question remains unanswered, specifically how the enterprises choose business architecture for each industry, which could be a subject of further research.

The results of the given research provide a data source for researchers and business architects within the SME sector, who successfully apply the models of business architecture in the enterprises operating in the sectors of manufacturing, industry, and services. The results may help start-ups in the process of designing their business architecture as well as the enterprises who has not applied the philosophy of the target business architecture so far.

\section{Conclusions}

In the period of globalization and glocalization processes, business architecture goes through the transformation, which leads enterprises to constant development. This development influences the decision-making of business architects and strategic behaviour of managers in enterprise management.

Evaluation of goal achievement. The objective of the contribution was to determine the effect of globalization and glocalization processes on the selected elements of business architecture in a test sample of 250 enterprises operating in the sectors of manufacturing, industry, and services in the South Bohemian Region of the Czech Republic. Using mathematical-statistical methods, the dependencies were confirmed for all selected analysed 
elements of business architecture (geographical scope of enterprises, levels of management structures, and type of organizational structure). The results showed that in the case of 3 and 4-level management, multinational enterprises with combined and departmental management structure are most influenced by the globalization processes. In contrast, the influence of glocalization processes was confirmed in the case of national and regional enterprises with 1 and 2-level form of management. The results obtained also pointed to the fact that as a result of globalization and glocalization processes, there is a gradual transformation of business architecture, which leads to the development and gradual transition from the centrallyplanned economy to the market economy.

Application in practice. In practice, the results of the given research may help strategic managers and business architects in the SME sector analyse trends in the organizational and management structures and in the decision-making processes related to selecting the form of organizational structure in the case of start-ups and the enterprises that have not started to apply the elements of business architecture. The research results are also useful for the researchers in the management and economics sectors.

Further research directions. Further research might be focused on the geographical extension of the dataset, research at the level of EU-27 countries, and a more detailed analysis of the selected elements of business architecture according to the individual sectors.

\section{References}

1. Arkhipov, A. Y., \& Yeletsky, A. N. (2021). Modern globalization: development of glocalization and fragmentation of the world economy. Multinational Journal of Sociology and Social Policy, 41(1-2), 224-238.

2. Buchalcevová, A., Gála, L. (2008). Architektura v podnikové informatice. Systémová integrace, 15(3), 7-22.

3. Bucur, I., Done, I., \& Bucur, C. (2010). Globalization Of Economic Development. Economic World Destiny: Crisis nd Globalization? Section I: Globalization and PostGlobalization (IECS)(pp. 153-159). Lucian Blaga Univ Sibiu, Romania.

4. Dumitrache, V., Balu, P. E., Alpopi, C., Ciobanu, G., \& Popescu, I. M. (2020). Globalization of the Economy: Causes, Risks, Effects. Proceedings of the 35th Multinational Business Information Management Association (IBIMA) (pp. 5070-5077). IBIMA Publishing.

5. Gála, L., Buchalcevová, A., \& Jandoš, J. (2012). Podniková architektura. Řepín: Tomáš Bruckner.

6. Gonçalves, D., Ferreira, L. \& Campos, N. (2021). Business architecture for high flexible and agile company in automotive industry. Procedia Computer Science, 181, 10771082.

7. Iermakova, O., Kaminska, B., Voicilas, D. M., Laiko, O., Hetman, O., Zabarna, E., \& Halytsia, I. (2021). Glocalization of Regional Innovation Development. Management Theory and Studies for Rural Business and Infrastructure Development, 43(2), 195-205.

8. Kislingerová, E., Nový, I. (2005) Chování podniku v globalizujícím se prostředí. Beckova edice ekonomie.

9. Moldagulova, A., Satybaldiyeva, R., Uskenbayeva, R., Kassymova, A., \& Kalpeyeva, Z. (2020). Architecture development for certain classes of university business processes. Proceedings - 2020 IEEE 22nd Conference on Business Informatics, CBI 2020, 2, (pp. 91-95). Institute of Electrical and Electronics Engineers Inc.

10. Pártlová, P., \& Váchal, J. (2017). Projekce podnikové architektury v podnicích ČR. Mladá veda, 5(7), 62-70. 
11. Pártlová, P., \& Straková, J. (2017). Podnikové organizační a řídící struktury na rozcestí. Trendy v podnikání, 7(1), 17-21.

12. Soviar, J., Holubčík, M., Vodák, J., Rechtorík, M., \& Pollák, F. (2019). The Presentation of Automotive Brands in the On-Line Environment - The Perspective of KIA, Peugeot, Toyota and VW in the Slovak Republic. Sustainability 11(7), Article 2132.

13. Stiglitz, J. E. (2021). Globalization in the aftermath of the pandemic and trump. Journal of Policy Modeling, 43(4), 794-804.

14. Radulović, M., Kostić, M. (2020). Globalization and economic growth of Eurozone economies. Proceedings of Rijeka Faculty of Economics: Journal of Economics and Business, 38(1), 183-214.

15. Váchal, J., \& Talíŕ, M. (2020). The Development of Organizational and Management Structures in Small-scale and Mid-scale Entrepreneurship in the Czech Republic. SHS Web of Conferences, 73, Article 02006.

16. Zhi, Q., \& Zhou, Z. (2022). Empirically Modeling Business Architecture Using ArchiMate. Computer Systems Science and Engineering, 40(1), 357-374. 